RASĀYAN J. Chem.

Vol. 13 | No. 3 |1394-1400| July - September | 2020 ISSN: 0974-1496 | e-ISSN: 0976-0083 | CODEN: RJCABP

\title{
SYNTHESIS, GROWTH AND CHARACTERIZATION STUDIES OF SEMI ORGANIC NLO L-VALINE CALCIUM NITRATE AND L-VALINE POTASSIUM NITRATE SINGLE CRYSTALS
}

\author{
S. Ramalakshmi ${ }^{1^{*}}$ and K.A. Vijayalakshmi ${ }^{2}$ \\ ${ }^{1}$ Department of Physics, Research and Development Center, Bharathiar University, Coimbatore \\ ${ }^{2}$ Department of Physics, Sri Vasavi College, Erode. \\ EE-mail: 21ramalakshmi1985@gmail.com
}

\begin{abstract}
These organic non-linear L-Valine potassium nitrate and L-Valine calcium nitrate crystals are grown at room temperature by slow evaporation techniques. The crystal structure was analyzed by powder X-ray method. The presence of a functional group can be identified by Fourier transform infrared spectrum (FT-IR). The second-order non-linear optical property is measured by the Kurtz powder technique. The optical behavior was analyzed by Ultraviolet -vis spectrum and found that the crystal is transparent in the region between the $200-1100 \mathrm{~nm}$.

Keywords: L-Valine, SHG, FT-IR. UV, EDAX
\end{abstract}

(C) RASĀYAN. All rights reserved

\section{INTRODUCTION}

The NLO materials have great attention due to their application in optoelectronics and data storage technologies. organic crystal has low thermal and mechanical properties. ${ }^{1}$ It's also has a low laser damage threshold and difficult to produce bulk size crystals. In inorganic, they have good thermal and mechanical properties but modest optical nonlinearities due to the shortage of extended $\pi$-electron delocalization. ${ }^{2-5}$ In semi-organic crystals, the organic ligands are stoichiometrically bound with the inorganic host. In recent years, semi-organic crystal has attracted great interest because they have high nonoptical linearity, chemical stability, good hardness and high resistance to laser-induced damage. L-Valine is an amino acid group that contain donate carboxylate group and accept amino acid group which gives noncentrosymmetric structures for crystals. ${ }^{6-15}$ This journal paper describes the synthesis of L-Valine Potassium nitrate and Calcium nitrate crystals. The grown crystal is characterized by X-Ray analysis, FTIR, Optical transmission spectra, SHG efficiency and EDAX.

\section{Synthesis and Crystal Growth}

\section{EXPERIMENTAL}

The commercially available material of L-valine, potassium nitrate and Calcium nitrate was received from Sisco Research Laboratories PVT. Ltd (India).This is a long recrystallization process and the available raw material is used one after purification. L-valine and potassium nitrate and L-Valine and Calcium nitrate is taken in a particular molar ratio and mixed in double-distilled water and stirred for $7 \mathrm{hrs}$. The stirred solution was filtered to remove unwanted particles. Then the dissolved solution was transferred to a beaker. The beaker was covered by an aluminum sheet. Some holes were made on the aluminium sheet for evaporation at room temperature. The grown crystal of LVPN and LVCN was colorless and good transparent obtained in 3 weeks.

\section{Chemical Reactions}

$$
\begin{aligned}
& \mathrm{C}_{5} \mathrm{H}_{11} \mathrm{NO}_{2}+\mathrm{KNO}_{3} \rightarrow \mathrm{C}_{5} \mathrm{H}_{11} \mathrm{NO}_{2} \cdot \mathrm{KNO}_{3} \\
& \mathrm{C}_{5} \mathrm{H}_{11} \mathrm{NO}_{2}+\mathrm{CaNO}_{3} \rightarrow \mathrm{C}_{5} \mathrm{H}_{11} \mathrm{NO}_{2} \cdot \mathrm{CaNO}_{3}
\end{aligned}
$$

Rasayan J. Chem., 13(3), 1394-1400(2020)

http://dx.doi.org/10.31788/RJC.2020.1335666 
RASĀYAN J. Chem.

Vol. 13 | No. 3 |1394-1400| July - September | 2020

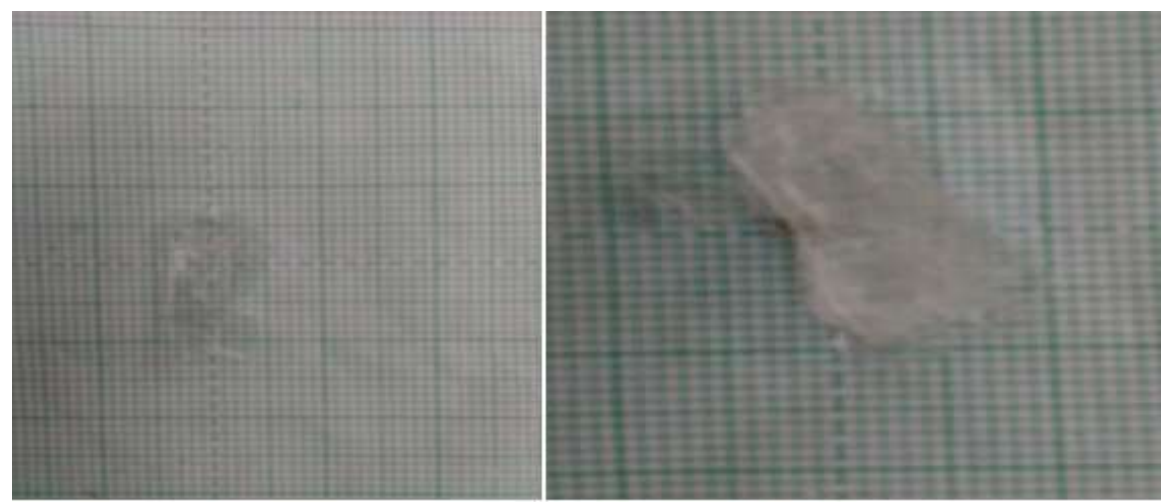

Fig.-1: L-Valine Calcium Nitrate and L-Valine Potassium Nitrate

\section{X-Ray Analysis}

\section{RESULTS AND DISCUSSION}

The grown crystal of L-Valine potassium nitrate and L-Valine Calcium nitrate were subjected to powder $\mathrm{X}$-ray diffraction analysis to confirm the crystal structure and lattice parameter by using XPERT PRO diffraction meter. The Sample was scanned over the required range for $2 \theta$ values $\left(10^{\circ}-50^{\circ}\right)$. The Lattice values of L-Valine potassium nitrate is $\mathrm{a}=9.788 \AA \mathrm{A}=6.532 \AA$ and $\mathrm{c}=12.00372 \AA \mathrm{Cell}$ vol $=436.11 \AA^{3}$. The lattice parameters for L-Valine Calcium nitrate is $\mathrm{a}=5.788 \AA \mathrm{A}, \mathrm{b}=7.532 \AA$ and $\mathrm{c}=10.00372 \AA$ cellvol $=436.11 \AA 3$. The recorded spectrum of LVPN and LVCN is shown in Fig. -2 .
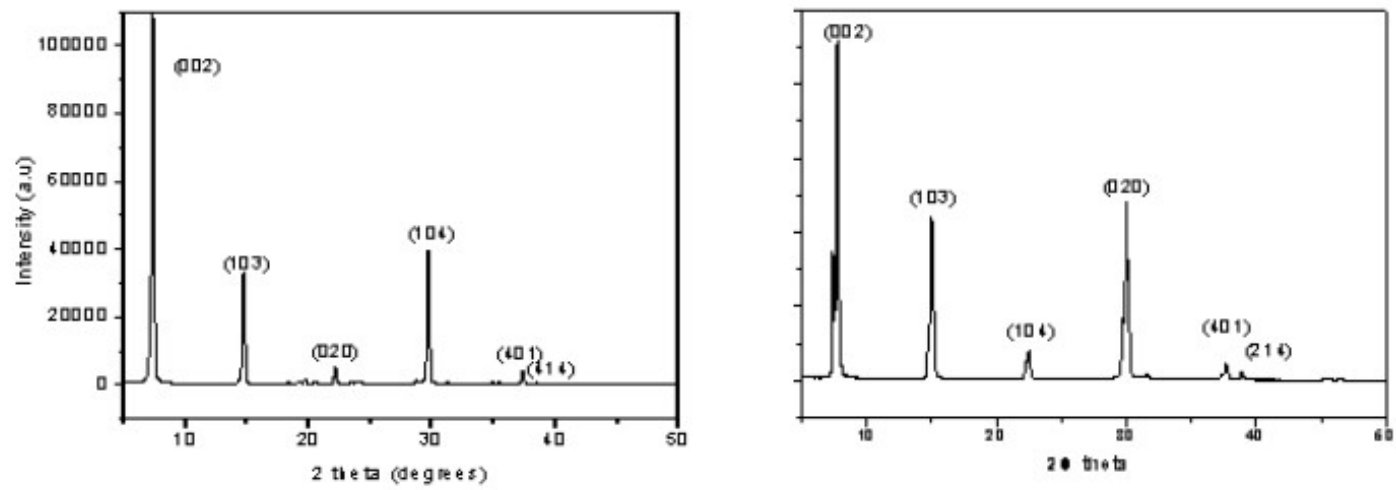

Fig.-2: XRD Pattern of L-Valine Potassium Nitrate and L-Valine Calcium Nitrate

The observed above result shows the grown crystal of L-Valine Potassium nitrate and L-Valine Calcium nitrate belongs to monoclinic.

\section{FT-IR Spectral Analysis}

The grown crystal of LVPN and LVCN were subject to FTIR analysis. It was recorded in the range of 400-4000 cm-1 employing a Perkin-Elmer spectrometer by the KBr pellet method. Figures-3 and 4 show the FTIR spectrum of crystal LVPN and LVCN. The vibrational frequency and their frequency assignment are presented in Table-1. The IR spectra of LVPN mainly arise due to internal vibration of functional groups $\mathrm{NH}_{3}{ }^{+}, \mathrm{CH}, \mathrm{CH}_{3}$ and $\mathrm{COOH}$. The sharp peak at 2966 is due to $\mathrm{CH} 2$ vibration of amino acid. The absorption peak 2627 and 2100 is due to N-H-O valence stretching combination and Combination band of NH3 bending vibrations. The absorption band at 1636 and 1500 corresponds to $\mathrm{NH} 3$ asymmetric stretching and NH3 symmetric stretching sharp peak at 3478 is due to $\mathrm{H}_{2} \mathrm{O}$ asymmetric stretching. In LVCN, the peaks at 2960, 2633 and 2367 are attributed to $\mathrm{CH}_{2}$ symmetric stretching, N-H$\mathrm{O}$ valence stretching combination and Overtones and combinations respectively. The peak at 2107 is due to $\mathrm{NH}_{3}{ }^{+}$degenerative deformation and $\mathrm{NH}_{3}{ }^{+}$torsion. The absorption band at 1636 and 1510 is due to $\mathrm{NH}_{3}$ asymmetric stretching and symmetric stretching. 
RASĀYAN J. Chem.

Vol. 13 | No. 3 |1394-1400| July - September | 2020

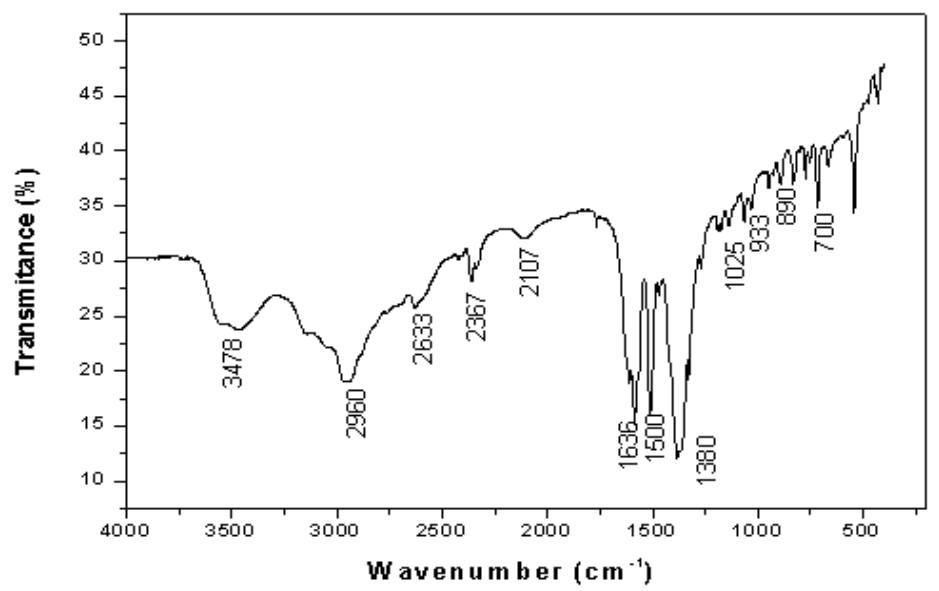

Fig.-3: FT-IR of of L-Valine with Calcium nitrate

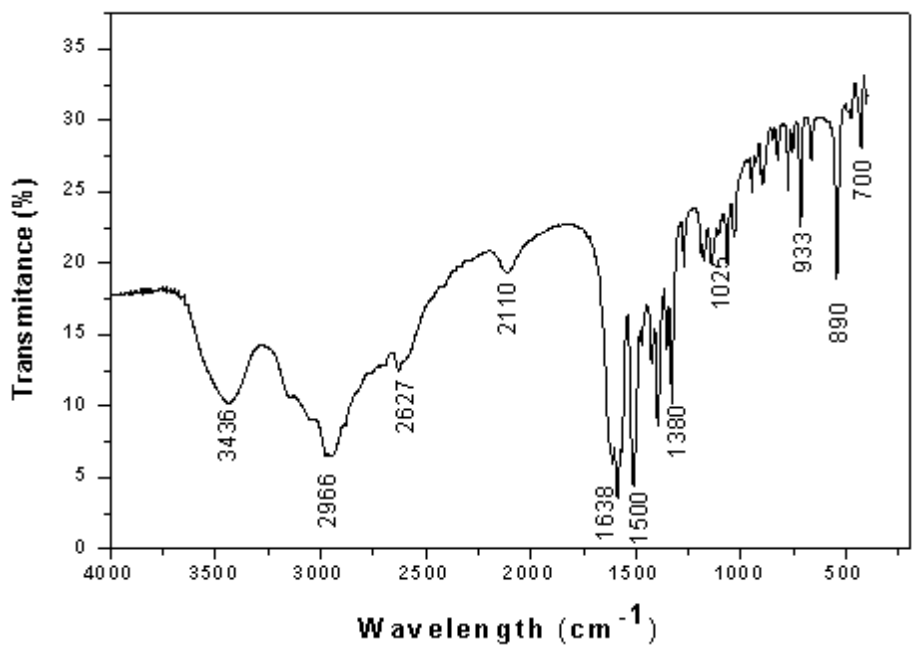

Fig.-4: FT-IR Analysis of L-Valine with Potassium Nitrate

Table-1: IR Frequencies of LVPN and LVCN

\begin{tabular}{c|c|c|c}
\hline \multirow{2}{*}{ IR peak } & \multirow{2}{*}{ Assignments } & \multicolumn{2}{c}{ Frequencies $\mathrm{cm}^{-1}$} \\
\cline { 3 - 4 } & & LVPN & LVCN \\
\hline 1 & $\mathrm{NH}_{2}$ asymmetric stretching of Thiourea & 3438 & 3478 \\
\hline 2 & $\mathrm{CH}_{2}$ symmetric stretching & 2966 & 2960 \\
\hline 3 & $\mathrm{~N}-\mathrm{H}-\mathrm{O}$ valence stretching combination & 2627 & 2633 \\
\hline 4 & $\begin{array}{l}\text { Combination band of } \mathrm{NH}_{3} \\
\text { bending vibrations }\end{array}$ & 2110 & 2107 \\
\hline 5 & $\mathrm{NH}_{3}$ asymmetric stretching & 1636 & 1632 \\
\hline 6 & $\mathrm{NH}_{3}$ symmetric stretching & 1500 & 1510 \\
\hline 7 & C-O stretching & 1380 & 1390 \\
\hline 8 & $\left(\mathrm{CH}_{3}\right)_{2}$ symmetricstretching & 1025 & 1030 \\
\hline 9 & $\mathrm{C}-\mathrm{CO}$ symmetric stretching & 933 & 955 \\
\hline 10 & $\mathrm{C}-\mathrm{C}-\mathrm{N}$ symmetric stretching & 890 & 910 \\
\hline
\end{tabular}

\section{Optical Transmission Spectra}

The transmittance range and cutoff wavelength are the most important parameter for optical application. The optical behavior of the crystal is studied using LAMBDA-35 spectrophotometer is shown in Figs. -5 and 6 . The spectrum recorded in the range of $200 \mathrm{~nm}-1100 \mathrm{~nm}$. The crystal has a lower cut-off wavelength 
RASĀYAN J. Chem.

Vol. 13 | No. 3 |1394-1400| July - September | 2020

of $280 \mathrm{~nm}(\mathrm{LVPN})$ and $272 \mathrm{~nm}(\mathrm{LVCN})$. Optical transmittance of about $60 \%$ is observed for $1.5 \mathrm{~mm}$ plates of L-Valine potassium nitrate and L-Valine Calcium nitrate crystals are adequately good for SHG.

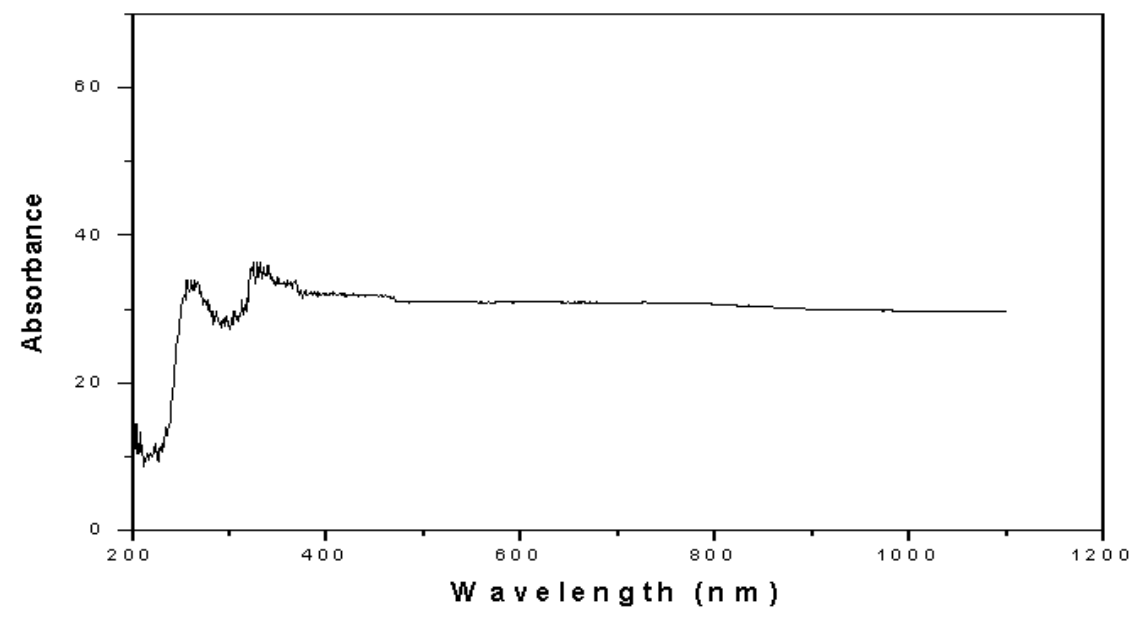

Fig.-5: UV for L-Valine with Calcium Nitrate

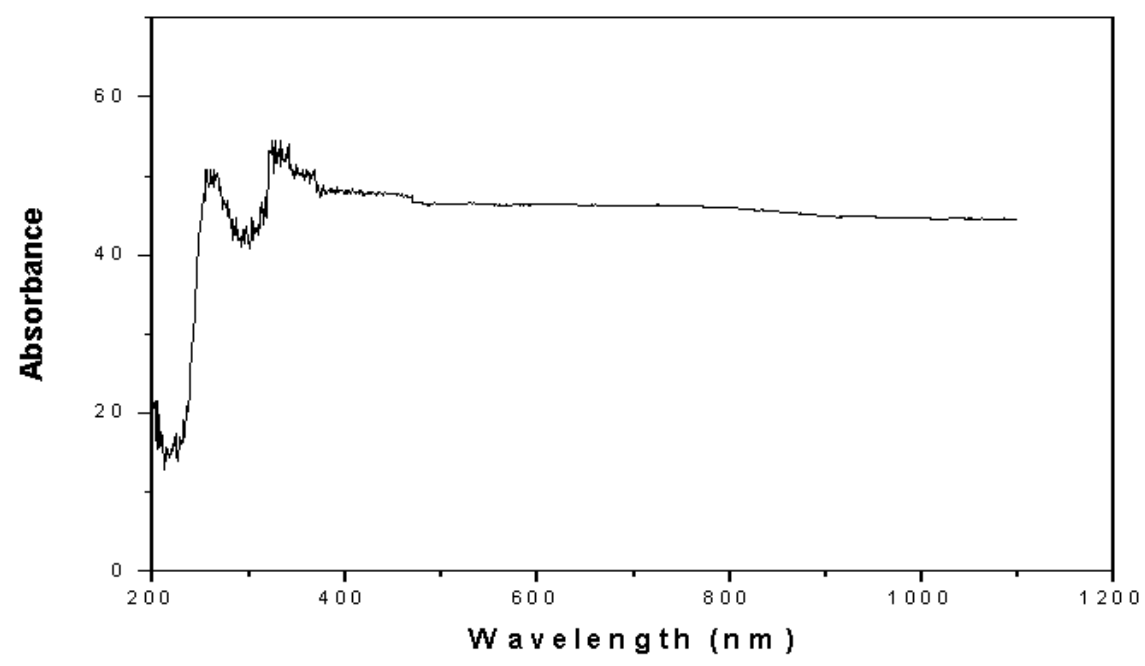

\section{SHG Measurement}

Fig.-6: UV for L-Valine with Potassium Nitrate

The second harmonic efficiency of the grown crystal LVPN and LVCN was performed by Kurtz and Perry powder SHG method. The sample could be compressed into uniform sized powdered and then the powdered crystal placed between two glass plates. The first harmonic radiation $(1064 \mathrm{~nm})$ of Q-switched Nd: YAG laser is allowed to fall on the sample with Pulse energy $4 \mathrm{ml} / \mathrm{pulse}$ and width $6 \mathrm{~ns}$. The second harmonic signal in the grown crystal is confirmed by the emission of green radiation from the sample. In this experiment, potassium dihydrogen phosphate is used as reference material. The SHG efficiency of LVPN and LVCN was 0.6 and 0.5 times that of potassium dihydrogen phosphate (KDP).

\section{Scanning Electron Microscope}

Surface study of LVPN and LVCN is carried out through JSM $6360 \mathrm{JEOL/EO} \mathrm{make.} \mathrm{The} \mathrm{utmost} \mathrm{possible}$ magnification in the apparatus is 3, 00, 000 times maximum with a resolution of $3 \mathrm{~nm}$. The crystal surface with a skinny layer of carbon to make the sample conducting. Figures- 7 and 8 show that the size of the crystals is $5 \mu \mathrm{m}$. It shows that the surface of the crystal is even and disorder free. 
RASĀYAN J. Chem.

Vol. 13 | No. 3 |1394-1400| July - September | 2020

Table-2: SHG Efficiency of LVPN and LVCN

\begin{tabular}{c|c|c|c}
\hline S. No. & Sample Name & $\begin{array}{c}\text { Energy Output } \\
\text { ( milli joule) }\end{array}$ & $\begin{array}{c}\text { Energy Input } \\
\text { (joule) }\end{array}$ \\
\hline 1 & $\begin{array}{c}\text { L-valine+potassium } \\
\text { nitrate }\end{array}$ & 5.08 & 0.701 \\
\hline 2 & $\begin{array}{c}\text { L-valine+Calcium } \\
\text { nitrate }\end{array}$ & 5.6 & 0.701 \\
\hline 3 & KDP (Reference) & 8.91 & 0.701 \\
\hline
\end{tabular}

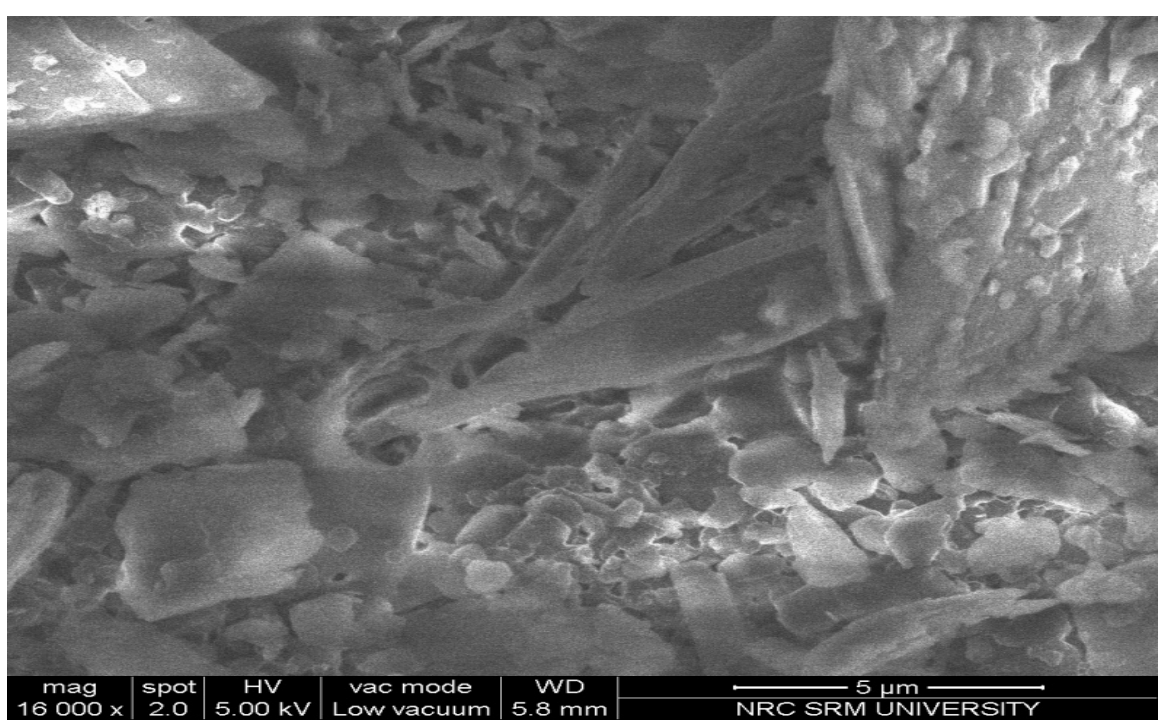

Fig.-7: SEM for L-Valine Potassium Nitrate

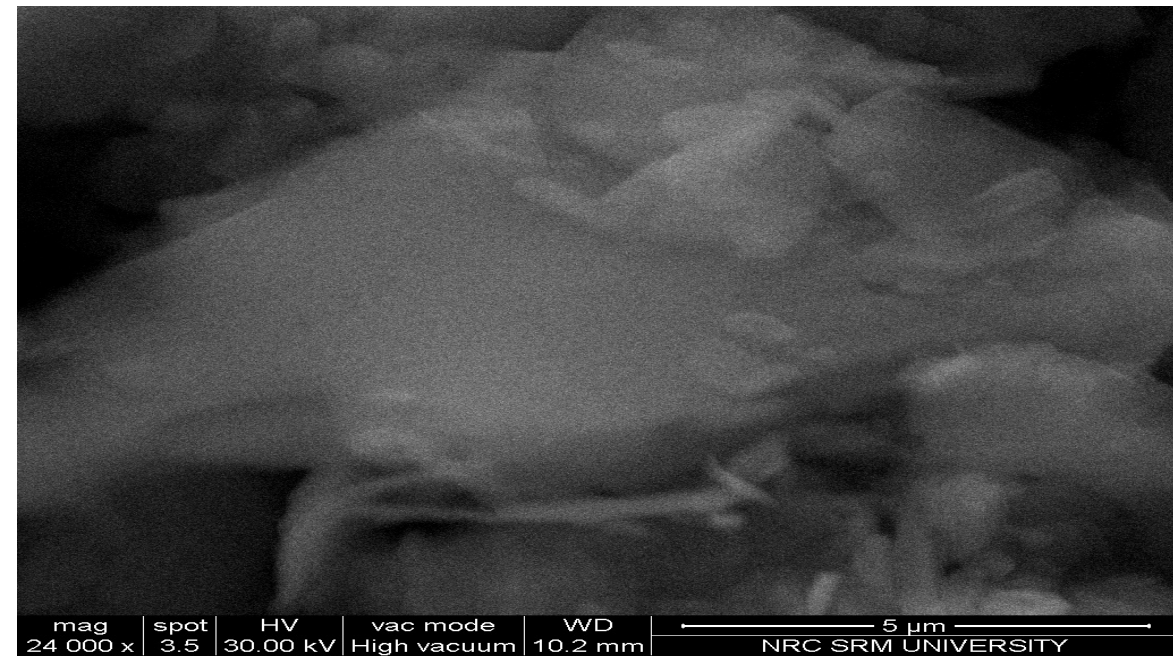

Fig.-8: SEM for L-Valine Calcium Nitrate Crystal

\section{EDAX Analysis}

The elements present in the grown crystal LVPN and LVCN was determined by using energy dispersive X-ray analysis (EDAX) measurements by using JEOL Model JED-2300 Energy Dispersive X-ray (EDAX). Microanalysis system attached to a JEOL JSM-6390LV scanning electron microscope (SEM) with a low vacuum solution of $4 \mathrm{~nm}$. Figure-9 shows the EDAX spectrum of L-ValinePotassium nitrate which reveals the presence of .potassium and nitrogen. Figure-10 illustrates the EDAX spectrum of LValineCalcium nitrate which reveals the presence of Calcium and nitrogen. 
RASĀYAN J. Chem.

Vol. 13 | No. 3 |1394-1400| July - September | 2020

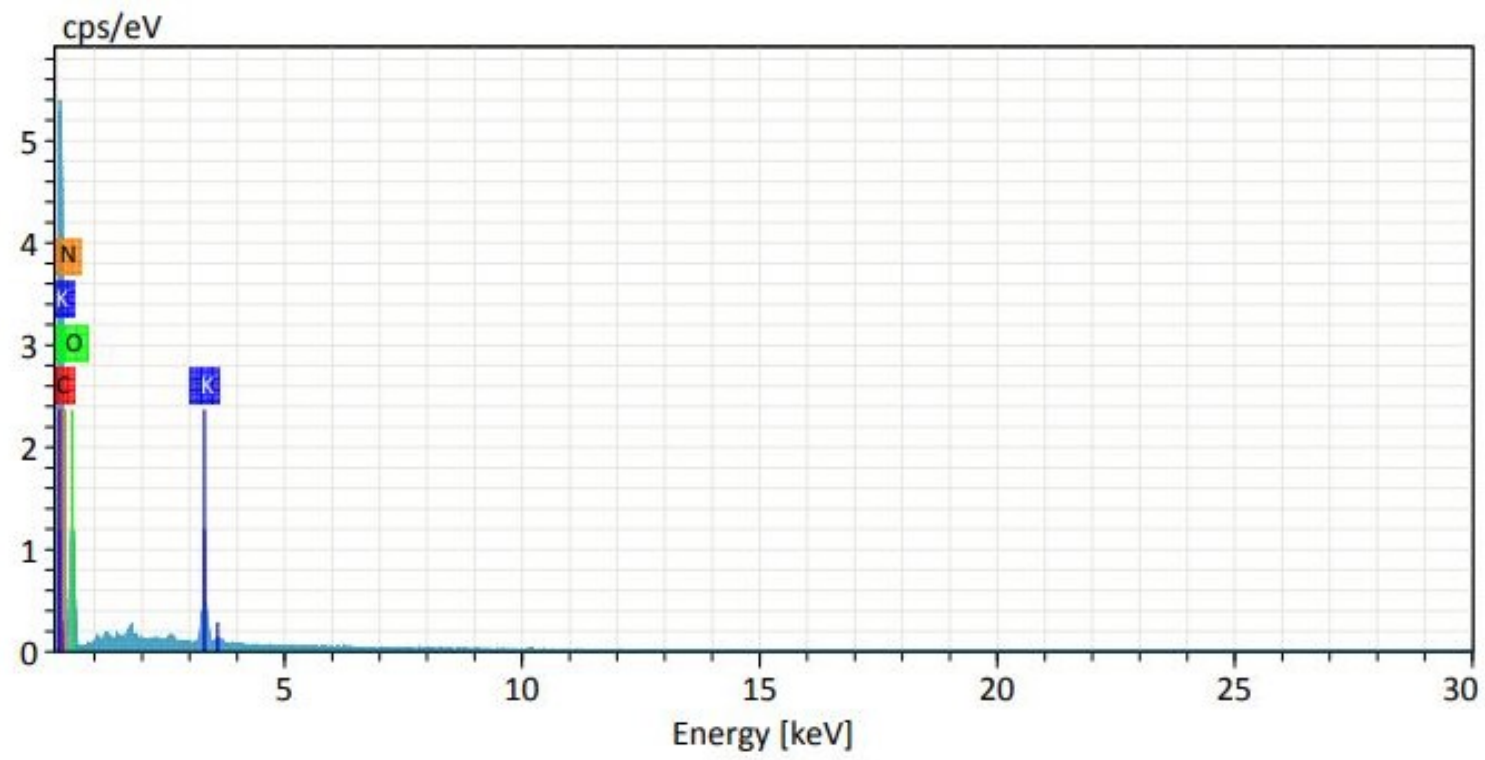

Fig.-9: EDAX for L-Valine Potassium Nitrate

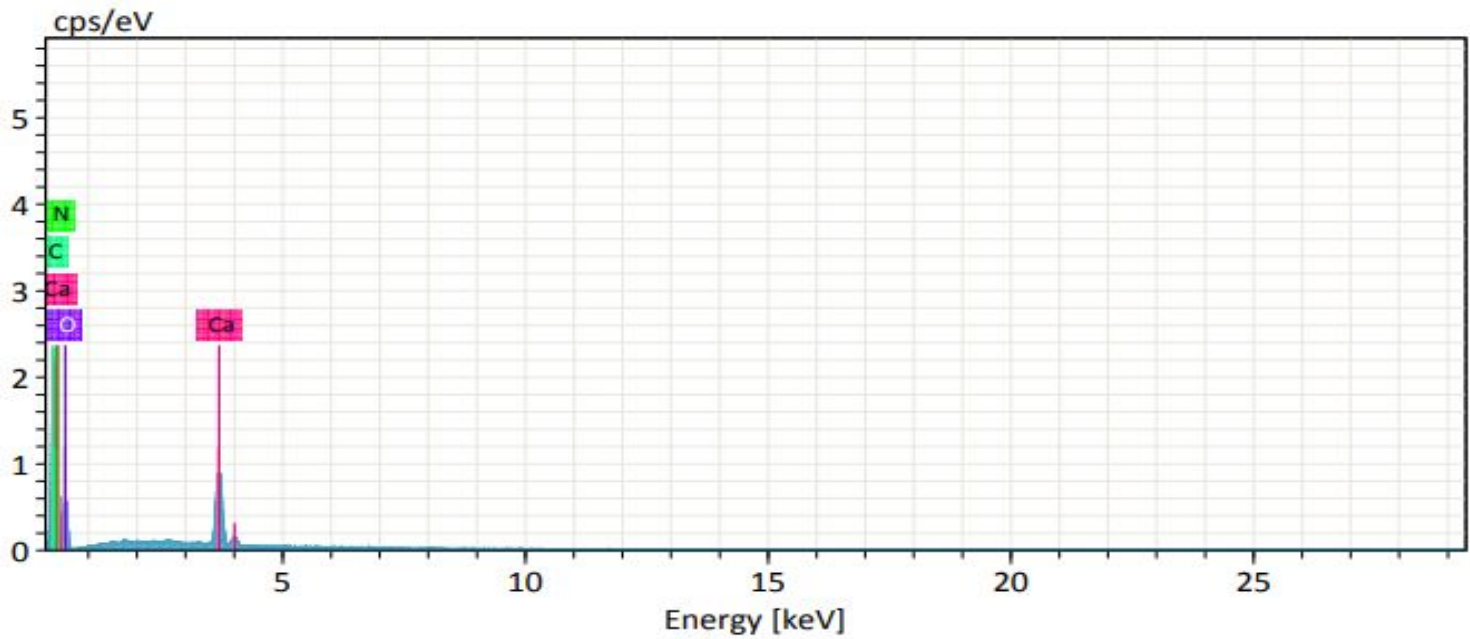

Fig.-10: EDAX for L-Valine Calcium Nitrate Crystal

\section{CONCLUSION}

By using slow evaporation technique to grow the Semiorganic crystals of L- Valine Potassium nitrate and Calcium nitrate at room temperature. The structure and lattice values can be measured from powder X-ray analysis. In the FTIR spectrum, the presence of various functional groups has been identified. The grown crystal has a good transmission window in the visible region between( 270 and 280) to $1100 \mathrm{~nm}$ suitable for NLO applications. The SHG efficiency of the grown LVPN and LVCN crystal having 0.6 \& 0.5 times than that of KDP.

\section{REFERENCES}

1. S. Palaniswamy and G.M. Sangeetha, Rasayan Journal of Chemistry, 2, 322(2009).

2. K. Ambujam, K. Rajarajan, S. Selvakumar, I. Vetha Potheher, Ginson P. Joseph and P. Sagayaraj, Journal of Crystal Growth, 286, 440(2006), DOI:10.1002/ crat.200510665

3. G. Ramesh Kumar, S. Gokul Raj, K.A. Bogle, S.D. Dhole, V.N. Bhoraskar, R. Mohan, Applied Surface Science, 254(16), 5231(2008), DOI: 10.1016/j.apsusc.2008.02.030.

4. P. A. Angeli Mary and S. Dhanuskodi, Crystal Research Technology, 36, 1231(2001), DOI: $10.1002 / 1521-4079(200111)$ 
RASĀYAN J. Chem.

Vol. 13 | No. 3 |1394-1400| July - September | 2020

5. G. Maruthi and R. Chandramani, Rasayan Journal of Chemistry,4, 280(2011).

6. P. Becker, Advanced Materials, 10, 979(1998), DOI:10.1002/(SICI)1521-4095(199809)10133.0.

7. R. N. Jayaprakash and P. Kumaradass, Oriental Journal of Chemistry, 29, 1409(2013), DOI: $10.13005 / \mathrm{ojc} / 290416$

8. S. Palaniswamy and O.N. Balasundaram, Rasayan Journal of Chemistry, 2, 782(2009).

9. H. J. Zhang, H. D. Jiang, Applied Physics A material science and Processing,78, 889(2004), DOI: 10.1007/s00339-003-2085-9

10. T. U. Devi, N. Lawrence, R. Ramesh Babu and K. Ramamurthi, Journal of Crystal Growth, 310, 116 (2008), DOI: 10.1007/s00339-003-2085-9

11. G. D. Andreetti, L. Cavalca and A. Musatti, Acta Crystallographica Section B, 24, 683(1968), DOI: $10.1107 /$ S056774086800302X

12. M. Arivanandhan, C. Sanjeeviraja, K. Sankaranarayanan, S.K. Das, G. K. Samanta and P. K. Datta,Optical Materials, 28, 324(2006), DOI: 10.1016/j.optmat.2004.07.024

13. V. Ramesh, K. Rajarajan, Applied Physics B, 113, 99(2013), DOI: 10.1007/s00340-013-5444-z

14. P. V. Dhanaraj, G. Bhagavannarayana and N. P. Rajesh, Materials Chemistry and Physics, 112, 490(2008), DOI:10.1016/j.matchemphys.2008.06.003

15. R. Siddheswaran, R. Sankar, M. Rathnakumari, R. Jayavel, P. Murugakoothan, and P. Sureshkumar, Laser Physics Letters, 12, 588(2006), DOI: 10.1002/lapl.200610058

[RJC-5666/2019] 